\title{
Evaluation of Medical College Students' Entrepreneurial Skills and Its Relationship with Social Intelligence
}

\author{
Jin $W u^{1}$, Linze $W u^{2}$ \\ ${ }^{1}$ Business School, Nanfang College, Sun Yat-sen University, Guangzhou, China \\ ${ }^{2}$ Department of Economy and Trade, Guangzhou College of Technology and Business, Guangzhou, China \\ Email: ruojincn@126.com, 1060052496@qq.com
}

How to cite this paper: $\mathrm{Wu}, \mathrm{J}$. and $\mathrm{Wu}$, L.Z. (2019) Evaluation of Medical College Students' Entrepreneurial Skills and Its Relationship with Social Intelligence. Open Journal of Social Sciences, 7, 13-23. https://doi.org/10.4236/jss.2019.74002

Received: March 13, 2019

Accepted: April 5, 2019

Published: April 8, 2019

Copyright () 2019 by author(s) and Scientific Research Publishing Inc. This work is licensed under the Creative Commons Attribution International License (CC BY 4.0).

http://creativecommons.org/licenses/by/4.0/

\section{c) (i) Open Access}

\begin{abstract}
Social intelligence and entrepreneurial skills are important factors influencing individual academic performance and career development. Studies have shown that people with high social intelligence have the ability to understand and manage others and have an advantage in innovation. The entrepreneurial personality trait is precisely the courage to innovate. Therefore, there is a close relationship between entrepreneurship and social intelligence. In this study, the author explores the relationship between students' social intelligence level and entrepreneurial skills based on medical college students. This study used a cross-sectional descriptive method for related research. The results showed that the overall scores of the entrepreneurial skills assessment criteria of the students were lower. This shows that students' performance levels of entrepreneurial skills are relatively weak. This result shows that we need to further improve the entrepreneurial skills of medical university students and take the necessary measures to improve students' social intelligence.
\end{abstract}

\section{Keywords}

Entrepreneurial Skills, Social Intelligence, Innovation, Medical College Students

\section{Introduction}

Studies have shown that people with high social intelligence have the ability to understand and manage others, and to take sensible actions in dealing with interpersonal relationships such as employees, customers, and distributors. More importantly, people with high social intelligence are far more innovative than 
those with low social intelligence [1]. The entrepreneurial personality trait is precisely the courage to innovate [2]. An entrepreneur needs to deal with relationships from stakeholders or organizations inside and outside the team, such as employees, shareholders, customers, suppliers and investors. This requires entrepreneurs to have good leadership, motivation, communication and negotiation skills [3]. Therefore, there is a close relationship between entrepreneurship and social intelligence.

Since General Secretary Xi Jinping put forward the conclusion that China's economic development has entered the "new normal" in the 2014 inspection tour in Henan, the State Council has made a major strategic deployment of mass entrepreneurship and innovation in a timely manner. Governments at all levels have recognized that the key to building prosperity and stimulating regional growth is to promote entrepreneurship among people, especially young people. Promoting youth entrepreneurship not only helps reduce unemployment, but more importantly, it allows young people to understand that they do not need to wait for jobs offered by others but should create their own future through entrepreneurship. In general, the career development of medical students generally follows a fixed pattern. Students accumulate a wealth of theoretical knowledge in the school. After graduation, they start with a doctor, then a resident, an attending physician, a deputy chief physician, and finally become a chief physician. However, with the continuous implementation of the enrollment expansion policy in many universities in China in recent years, the employment situation of medical students has become increasingly severe, and the employment rate has been declining. In order to achieve employment and expand employment methods, medical students must transform their traditional career development models and actively explore their own entrepreneurial path [4]. With the continuous development of China's economy, the quality of life and income of the people have been significantly improved, and people are paying more and more attention to their own health. According to the relevant provisions of the "Several Opinions on Promoting the Development of Health Service Industry" issued by the State Council in October 2013 (G.F. [2013] No. 40), it is clear that "we must mobilize social forces extensively and take measures to develop health service industry. In 2020, the total scale of the health service industry has reached more than 8 trillion yuan, becoming an important force for promoting sustainable economic and social development." Given the important position of the medical and health industry in the national economy and the strong support of national policies, the development potential of China's medical service market is very optimistic. This provides more market opportunities for medical students to start a business.

In articles about medical students' entrepreneurship, the focuses of scholars are on the status quo of entrepreneurship [5] [6], entrepreneurial barriers [7] [8], entrepreneurship education [9] [10] [11], entrepreneurial awareness [12] [13] and other aspects. Few people analyze the entrepreneurial behavior of medical students from the perspective of personality traits. Starting from the theory 
of social intelligence, this study explores the relationship between students' social intelligence level and entrepreneurial skills, filling the gaps in current research.

\section{Literature Review}

As early as 1920, Edward Thorndike proposed the concept of social intelligence. His interpretation of social intelligence is the ability of individuals to be in interpersonal relationships, to be able to understand others, to maintain good relationships with others, and to take wise actions. With the continuous development of social intelligence research, this concept has been continuously deduced and developed. Liu Xilang [14] believes that social intelligence is a set of cognitive abilities of human beings, enabling us to understand the world around us and learn how to solve problems. Sociologist Ross Honey will believe that social intelligence is a comprehensive set of indicators for evaluating individuals that include self-awareness, social awareness, social beliefs and attitudes, and the ability to manage complex social changes. Some scholars believe that social intelligence includes the ability of individuals to recognize and control their own and others' emotions. Individuals can identify different emotions and use the emotional information to influence and guide their own thinking and behavior, or to manage and adjust their emotions to adapt to the environment to achieve their goals [15].

Based on the above viewpoints, social intelligence directly affects how people recognize themselves and their surroundings, and thus takes actions that meet their own goals. In the process of entrepreneurship, the difference in the performance of entrepreneurs in social intelligence will affect the performance of their entrepreneurship to a certain extent. Successful entrepreneurs make the best decisions through self-innovation under worst-case conditions, and are aware of adverse environmental factors, market opportunities, and threats. In addition, successful entrepreneurs can correctly recognize themselves and the emotions of their counterparties from the very beginning in the process of innovation. Therefore, these people can maintain a relatively calm state, which in turn can control the self and the emotions of others. In fact, social intelligence helps entrepreneurs dominate their emotional lives while correcting past psychological habits and reducing internal challenges. It is because of social intelligence that the level of insight and intelligence of entrepreneurs is enhanced, thereby increasing the level of organizational strategy development and implementation [16]. Therefore, there is a close relationship between social intelligence and entrepreneurship. Lueger's study shows that entrepreneurial personality traits are closely related to the creation of entrepreneurship. Social intelligence, as a behavioral tendency and individual cognition, has a high degree of social roots, which is related to the human identification process and the ability to apply information. Therefore, it is considered a personal characteristic rather than a diagnostic consciousness [17]. 
For the prediction of the behavior of individual entrepreneurs in the organizational environment, social intelligence can also be used as one of the indicators for evaluating entrepreneurial competence standards. The results of the study show that employee perceived employee sentiment can greatly affect employees' entrepreneurial behavioral tendencies [18]. In the report on college students' entrepreneurial research, students with high levels of social intelligence are more inclined to control their emotions [19]. Therefore, when they are more confident, they can better control the various tasks within the unit. This allows them to be more entrepreneurial [20].

In research on organizational entrepreneurship, organizational-level entrepreneurship and entrepreneurial behavior can be seen as a new competitive advantage for companies [21]. Entrepreneurial behavior in an organization refers to all activities related to the discovery, assessment, and development of opportunities made by members of the organization [22]. Whether entrepreneurs in the organization can successfully explore market opportunities, conduct effective organizational entrepreneurship, and achieve the goal of increasing the competitive advantage of the company is largely related to the individual entrepreneurial motives [23]. Empirical research shows that entrepreneurial sentiment, one of the important resources of entrepreneurship, plays a positive role in stimulating entrepreneurial entrepreneurship [24]. In particular, managers' ability to control emotions and thoughts has a positive impact on existing entrepreneurial behavior in the organization [25].

In the study of the relationship between college students' social intelligence and entrepreneurship in China and abroad, foreign scholars generally believe that there is a significant correlation between college students' social intelligence level and entrepreneurial behavior. Because individuals with higher levels of social intelligence are more inclined to rationalize and reasonably control their emotions. Good emotional management can enable them to develop effective and reasonable ways and behaviors in their university studies. These methods and behaviors will be an important factor in their active entrepreneurship [26] [27]. In the domestic university student entrepreneurship research survey, one of the many factors that cause college students to fail in business is the lack of sufficient social intelligence, which is generally manifested in the absence of emotional management. Faced with various uncertainties and setbacks, college students have relatively weak psychological adjustment ability [28]. According to an empirical analysis, the emotional intelligence of college students has a significant relationship with entrepreneurial ability. There are significant differences in the entrepreneurial ability of college students with different levels of emotional intelligence, and the entrepreneurial ability of college students with high levels of emotional intelligence is stronger. Emotional intelligence has a strong predictive power for entrepreneurial ability [29].

In short, entrepreneurs need to have a high level of social intelligence including healthy psychology, good emotional management and so on. Taking into account the importance of entrepreneurship in Chinese society and as a neces- 
sary component of assessing students' comprehensive ability-social intelligence, we conducted this study to assess the relationship between entrepreneurial skills and social intelligence. The research is based on medical college students, mainly because the domestic medical and health industry plays an increasingly important role in the national economy. Coupled with the strong support of national policies, the development potential of China's medical service market is very optimistic. Such a social environment provides more market opportunities for medical students to start a business. Therefore, we conducted this study at the medical school of a university in the Mainland.

\section{Research Method}

In this study, cross-sectional descriptive methods were used for related research. The statistical population includes all students in the 2016 and 2017 sessions of a university medical school in the Mainland, including 3320 students (60\% female students and $40 \%$ male students). A systematic random sampling method was used to select 350 students for sample survey.

The study used two questionnaires to collect data; the first questionnaire was about entrepreneurial skills assessment. According to research by Smith et al., entrepreneurs' skills assessment criteria include creativity, environmental recognition, operational capabilities, financial knowledge, marketing knowledge, business concepts, etc. [30]. In addition, the standard entrepreneurship questionnaire validated by Kurdnaeich et al. [31] also evaluated entrepreneurial skills. The Cronbach's Alpha (Cranbach coefficient) of the questionnaire was 0.92 (25). The questionnaire included 83 questions based on the Likert scale (strongly agree, agree, disagree, strongly disagree). The minimum score for this questionnaire is 95 and the maximum score is 380 . The evaluation criteria for the entrepreneurial scores and their constituent elements in the Kurdnaeich et al. questionnaire are shown in Table 1. Since the questionnaire of Kurdnaeich et al. [31] has specific evaluation criteria, it is easy to judge students' entrepreneurial skills. Therefore, this questionnaire was used in this study. The second

Table 1. Entrepreneurial skill evaluation standard based on component separation.

\begin{tabular}{ccccc}
\hline Category & Very poor & Poor & Good & Very good \\
\hline Risk endurance & $18-43$ & $44-51$ & $52-57$ & $52-72$ \\
Control point & $17-49$ & $50-55$ & $56-60$ & $61-68$ \\
Achievement needs & $15-44$ & $45-48$ & $49-53$ & $54-60$ \\
Mental health & $13-34$ & $35-38$ & $39-43$ & $44-52$ \\
Pragmatism & $8-25$ & $26-28$ & $29-30$ & $31-32$ \\
Ambiguity tolerance & $11-18$ & $19-22$ & $23-26$ & $27-44$ \\
Positive thinking & $7-19$ & $20-21$ & $22-23$ & $24-28$ \\
Challenge & $6-16$ & $17-19$ & $20-21$ & $22-24$ \\
Total entrepreneurial skills & $95-248$ & $249-283$ & $284-303$ & $304-380$ \\
\hline
\end{tabular}


questionnaire is a social intelligence questionnaire compiled by Cai Xiaoyue and $\mathrm{Du}$ Jianbin [32] for the characteristics of Chinese college students. This questionnaire is adopted mainly because the social intelligence questionnaires currently used in China are mostly foreign social skills (SSI) scales. The content of this scale does not reflect the social intelligence characteristics of the Chinese. In addition, this scale did not make a targeted measurement. The psychological characteristics of college students, middle school students, primary school students, and other social groups vary. The research object of this paper is college students, so it is more reasonable to adopt the social intelligence questionnaire for college students' socialization. According to Cai Xiaoyue and Du Jianbin [32], college students' social intelligence includes social cognition, social skills, and social maturity.

In this study, two descriptive and inferential statistical methods were used for data analysis. At the descriptive level, the Pearson correlation coefficient is used at the inferred statistical level using the average correlation coefficient and the standard deviation. To this end, SPSS software is used (version 20).

\section{Analysis Result}

We found that the overall scores of the entrepreneurial skills assessment criteria for students were low, only $(213.45 \pm 2.08)$. This shows that students' performance levels of entrepreneurial skills are relatively weak. Although the risk tolerance $(56.13 \pm 1.76)$, ambiguity tolerance $(19.63 \pm 1.8)$, and challenge (31.83 \pm 1.9) are relatively good, it is not negligible that the scores in the remaining five evaluation criteria are poor or very poor. Students in the University of Medical Sciences scored poorly on both mental health $(32.09 \pm 1.18)$ and positive thinking $(19.76 \pm 2.06)$. The control points $(36.19 \pm 1.82)$, the achievement needs $(35.71 \pm 1.03)$ and the pragmatism scores are very poor. See Table 2 for details.

In addition, based on the Pearson correlation coefficient analysis of the relationship between social intelligence and various entrepreneurial skills, the results

Table 2. Average value and standard deviation of student scores in each entrepreneurial skill group.

\begin{tabular}{ccc}
\hline Category & $\mathrm{M} \pm \mathrm{SD}$ & Evaluation result \\
\hline Risk tolerance & $56.13 \pm 1.76$ & Good \\
Control point & $36.19 \pm 1.82$ & Very poor \\
Achievement needs & $35.71 \pm 1.03$ & Very poor \\
Mental health & $32.09 \pm 1.18$ & Poor \\
Pragmatism & $21.03 \pm 1.38$ & Very poor \\
Ambiguity tolerance & $19.63 \pm 1.8$ & Good \\
Positive thinking & $19.76 \pm 2.06$ & Poor \\
Challenge & $31.83 \pm 1.9$ & Good \\
Total score of entrepreneurial skills & $213.45 \pm 2.08$ & Poor \\
\hline
\end{tabular}


show that there is a statistically significant correlation between the two variables of social intelligence and entrepreneurial skills. The specific data is shown in Table 3.

\section{Data Description}

From the average of the indicators of the students' entrepreneurial skill evaluation criteria, in addition to risk-taking, ambiguity tolerance and challenges, students have weaknesses in control points, achievement needs, mental health, pragmatism, and positive thinking. Therefore, the overall level of entrepreneurial skills of medical students is not high. According to the existing research on the relationship between social intelligence and entrepreneurial skills, the social intelligence level of entrepreneurs directly affects the performance of entrepreneurship. People with high levels of social intelligence can better control their own and other people's emotions and correct their bad psychological habits, so their level of insight and intelligence is higher than those with lower levels of social intelligence. Therefore, entrepreneurs with high levels of social intelligence can better identify and challenge decisions based on their own challenges in various market environments [16]. In medical college students, there is a positive correlation between social intelligence and entrepreneurial skills. This study is consistent with the findings of Bahadori [33]. In Bahadori's [33] survey, entrepreneurial emotional management has had a significant positive impact on entrepreneurial behavior. The better the emotional management of entrepreneurs, the higher the likelihood of entrepreneurial success. Through this survey of medical students, we found a direct relationship between control points and social intelligence. These two variables have statistical significance in the relationship between social intelligence and achievement needs. This finding is consistent with the results of Chen Quan [34] and Chen Quan, Yin Zhiguo [35] on the relationship between emotional intelligence and achievement motivation, social achievement and mental health of college students. In their research survey,

Table 3. Correlation coefficient and significance level of social intelligence and entrepreneurial skill evaluation criteria.

\begin{tabular}{ccc}
\hline \multirow{2}{*}{ Entrepreneurial skill component } & \multicolumn{2}{c}{ Social intelligence } \\
\cline { 2 - 3 } Risk tolerance & P value & Correlation coefficient \\
Control point & 0.012 & 0.36 \\
Achievement needs & 0.037 & 0.18 \\
Mental health & 0.001 & 0.83 \\
Pragmatism & 0.028 & 0.19 \\
Ambiguity tolerance & 0.034 & 0.58 \\
Positive thinking & 0.029 & 0.58 \\
Challenge & 0.004 & 0.39 \\
\hline
\end{tabular}


there is a positive correlation between college students' emotional intelligence and social achievement, and academic achievement is not significantly correlated with achievement motivation [34] [35]. On the level of relationship between social intelligence and mental health, we find that there is a significant positive correlation between these two variables. This result is consistent with $\mathrm{Bi}$ Yanhua's [36] empirical findings on the social intelligence and mental health of normal university students. There is also a significant positive correlation between the social intelligence and mental health of normal university students. The level of mental health plays an important role in student employment and entrepreneurship [37]. There is a certain relationship between the two variables in social intelligence and students' tolerance for ambiguity. In the entrepreneurial process of entrepreneurship, innovation ability is an important factor in determining the success of entrepreneurship. The strength of innovation and the degree of tolerance for ambiguity are significantly positively correlated [38]. Finally, for students' positive thinking, pragmatism, and the relationship between risk taking and social intelligence. In this survey, there is a certain relationship between positive thinking and social intelligence, pragmatism and social intelligence, risk taking and social intelligence. At present, domestic and international research on positive thinking, pragmatism, and the relationship between risk-taking and social intelligence is still relatively lacking, especially in the context of entrepreneurship.

\section{Conclusion}

In this article, the authors analyze the relationship between social intelligence and entrepreneurship skills in Chinese medical college students. From the result of the assessment, in addition to the risk score, ambiguity tolerance, and challenges, the scores are relatively good, and the other scores are in poor and very poor levels. As a result, students' entrepreneurial skills total score is not high. In the survey of entrepreneurial skills and social intelligence, there is a statistically significant correlation between these two variables. This shows that we need to further improve the entrepreneurial skills of medical university students and take the necessary measures to improve students' social intelligence. In future research, scholars can focus on investigating positive thinking, pragmatism, and empirical research on the relationship between risk-taking and social intelligence, especially in entrepreneurial situations.

\section{Acknowledgements}

The project was supported by the Research Center for Cross-Border E-Commerce of the Belt and Road, Industry University Research Platform, Nanfang College of Sun Yat-sen University.

\section{Conflicts of Interest}

The authors declare no conflicts of interest regarding the publication of this paper. 


\section{References}

[1] Humphrey, R.H. (2013) The Benefits of Emotional Intelligence and Empathy to Entrepreneurship. Entrepreneurship Research Journal, 3, 287-294. https://doi.org/10.1515/erj-2013-0057

[2] Yang, W. (2013) Research on Personality Traits of Successful Entrepreneurs. Shaanxi Normal University, Xi'an.

[3] Song, K. (2004) Reflections on the Issues of Entrepreneurial Teams. Studies in Economics and Management, No. 2, 54-56.

[4] Zhong, H. and Ge, X. (2016) Research on the Core Competence of Students in Medical Colleges. Read the World, No. 9.

[5] Hu, Y. (2014) Investigation on the Current Situation of Self-Employment of College Students in Medical Colleges. Chinese University Graduates, No. 22, 59-64.

[6] Qiu, T. (2016) Investigation and Analysis of the Status Quo of College Students' Entrepreneurship. Journal of New Campus, No. 5, 154-154.

[7] Bai, Y. (2015) Problems in Student Entrepreneurship in Medical Colleges and Their Corresponding Measures. Youth, No. 2, 91.

[8] Zheng, W. and Meng, X. (2013) Entrepreneurial Bottlenecks and Solutions of Medical College Students. Journal of Shenyang Normal University (Social Science Edition), 37, 97-99.

[9] Wang, Y., Shi, J. and Liu, G. (2009) Construction of Implementation System of College Students' Entrepreneurship Education. Modern Education Management, No. 3, 116-118.

[10] Zhao, Y. (2014) Research on Innovation of College Students' Entrepreneurship Education. School Party Construction and Ideological Education, No. 12, 63-64.

[11] He, Q. (2018) Exploration of the Entrepreneurship Education Model of Medical Students in the "Internet+" Era. Education and Occupation, No. 2.

[12] Fan, C., Chen, X. and Wang, Y. (2014) Investigation on the Status Quo of Influencing Factors of Undergraduate Entrepreneurship in Medical Universities-Taking Universities in Guangzhou as an Example. Higher Education Research, No. 4, 173-176.

[13] Du, X. (2012) Problems and Improvement Measures of College Students' Entrepreneurship Education. Medical Education Research and Practice, 20, 865-867.

[14] Liu, X. (1998) Social Situation and Social Intelligence Training. Educational Research, No. 10, 34-39.

[15] Boyatzis, R.E., Gaskin, J. and Wei, H. (2015) Emotional and Social Intelligence and Behavior. In: Handbook of Intelligence, Springer, New York, 238-260.

[16] Goleman, D. (1996) Emotional Intelligence. Why It Can Matter More than IQ. Learning, 24, 217-236.

[17] Wong, C.S. and Law, K.S. (2002) The Effects of Leader and Follower Emotional Intelligence on Performance and Attitude: An Exploratory Study. Leadership Quarterly, 13, 243-274. https://doi.org/10.1016/S1048-9843(02)00099-1

[18] Marcus, B., Goffin, R.D., Johnston, N.G., et al. (2007) Personality and Cognitive Ability as Predictors of Typical and Maximum Managerial Performance. Human Performance, 20, 275-285. https://doi.org/10.1080/08959280701333362

[19] Wang, Y. and Wang, C. (2007) Research on the Characteristics of Emotional Intelligence of Freshmen. Journal of Beijing Institute of Technology (Social Science Edition), 9, 106-109. 
[20] Brundin, E., Patzelt, H. and Shepherd, D.A. (2008) Managers' Emotional Displays and Employees' Willingness to Act Entrepreneurially. Journal of Business Venturing, 23, 221-243. https://doi.org/10.1016/j.jbusvent.2006.10.009

[21] Covin, J.G. and Miles, M.P. (1999) Corporate Entrepreneurship and the Pursuit of Competitive Advantage. Entrepreneurship Theory \& Practice, 23, 47-63. https://doi.org/10.1177/104225879902300304

[22] Kuratko, D.F., Ireland, R.D., Covin, J.G., et al. (2005) A Model of Middle-Level Managers' Entrepreneurial Behavior. Entrepreneurship Theory \& Practice, 29, 699-716. https://doi.org/10.1111/j.1540-6520.2005.00104.x

[23] O’Boyle, E.H., Humphrey, R.H., Pollack, J.M., et al. (2011) The Relation between Emotional Intelligence and Job Performance: A Meta-Analysis. Journal of Organizational Behavior, 32, 788-818.

[24] He, L., Zhang, Y. and Song, Z. (2017) Research on the Relationship between Entrepreneurial Emotion and Entrepreneurial Behavior Tendency. Research and Development Management, 29, 13-20.

[25] Mair, J. (2002) Entrepreneurial Behavior in a Large Traditional Firm: Exploring Key Drivers. Social Science Electronic Publishing, 10, 49-72.

[26] Bahadori, M. (2012) The Effect of Emotional Intelligence on Entrepreneurial Behavior: A Case Study in a Medical Science University. Asian Journal of Business Management, 4, 81-85.

[27] Kanonuhwa, M., Rungani, E.C. and Chimucheka, T. (2018) The Association between Emotional Intelligence and Entrepreneurship as a Career Choice: A Study on University Students in South Africa. SA Journal of Human Resource Management, 21.

[28] Lin, S. (2016) Summary of Entrepreneurial Failure: Studying Tradition, Frontier Issues and Future Opportunities. Science of Science and Management of S. \& Technology, 37, 58-67.

[29] Chen, Q. and Shi, G. (2013) An Empirical Study on the Relationship between Emotional Intelligence and Entrepreneurial Ability of College Students. Journal of Education Management, 7, 109-114.

[30] Smith, W.L., Schallenkamp, K. and Eichholz, D.E. (2007) Entrepreneurial Skills Assessment: An Exploratory Study. International Journal of Management \& Enterprise Development, 4, 179-201.

[31] Kurdnaeich, A., Zali, M.R., Human, H.A. and Shams, S.H. (2007) Evaluation Tools of Personality Characteristics of Iranian Entrepreneurs. Tarbiat Modares University Press, Tehran.

[32] Cai, X. and Du, J. (2011) Research on Social Intelligence Measurement of College Students. Journal of Southwest University (Social Science Edition), 37, 168-172.

[33] Bahadori, A.A., Baalen, M.V., Shavers, M.R., et al. (2012) Dosimetric Impacts of Microgravity: An Analysis of 5th, 50th and 95th Percentile Male and Female Astronauts. Physics in Medicine \& Biology, 57, 1047-1070.

[34] Chen, Q. (2007) Research on the Relationship between Emotional Intelligence and College Students' Achievement Motivation, Social Achievement and Mental Health. Nanjing Medical University, Nanjing.

[35] Yin, Z. and Chen, Q. (2012) Research on the Relationship between Emotional Intelligence, Academic Achievement and Social Achievement of College Students. Education and Occupation, No. 35, 83-85.

[36] Bi, Y. (2007) The Relationship between Social Intelligence and Mental Health of 
Normal University Students. Zhengzhou University, Zhengzhou.

[37] Cheng, R. (2017) Employment-Oriented Ideological and Political Education for College Students. Journal of Educational Development Research, s1, 36-37.

[38] Stoycheva, K. (2008) The New and the Best: Ambiguity Tolerance and Creativity Motivation. International Journal of Psychology, 43, 6. 